\title{
A Utilização do Resíduo da Fabricação de Granilha em Engobes e Esmaltes Cerâmicos
}

\author{
Gian Garciaa*, Aline Resmini Meloa , Ana Sônia Mattosa, Maicon Costa Colombo , \\ Morgana Nuernberg Sartor Faraco ${ }^{a}$ \\ ${ }^{a}$ Departamento de Engenharia Química, Faculdade Satc, Criciúma, SC, Brasil \\ ${ }^{b}$ Empresa Colorminas - Colorifício e Mineração, Içara, SC, Brasil \\ *e-mail:aline.melo@satc.edu.br
}

\begin{abstract}
Resumo
O processo de produção da granilha cerâmica gera uma grande quantidade de resíduo. O descartado incorreto desse subproduto pode resultar em prejuízos para a empresa e impactos ambientais. O presente trabalho visa o desenvolvimento de um engobe e um esmalte cerâmico que utilize o maior percentual possível desse resíduo em sua formulação, em substituição às fritas, usualmente caras, sem alteração das características técnicas dos produtos. Diferentes percentuais de substituição foram avaliados. Os resultados das análises visuais foram satisfatórios. Obteve-se um esmalte com ótima textura, brilho e tonalidade menos amarelada e um engobe com brancura muito próxima do padrão de referência. As caracterizações físicas também levaram a bons resultados. $\mathrm{O}$ esmalte desenvolvido mostrou-se resistente ao lascamento e com coeficiente de dilatação térmica adequado. $\mathrm{O}$ engobe apresentou fusibilidade similar ao engobe padrão e mancha d'água aceitável. A análise econômica estimou uma redução de custo de 6,52\% para o engobe e 3,57\% para o esmalte com o uso do resíduo. Concluiu-se, portanto, que a produção de um engobe e um esmalte através da incorporação do resíduo de granilha na formulação é tecnicamente e economicamente viável.
\end{abstract}

Palavras-chave: resíduo de granilha, engobe, esmalte, redução de custo.

\section{Introdução}

A indústria cerâmica é a principal atividade econômica da região sul catarinense, reconhecida internacionalmente como um polo cerâmico (COLONETTI, 2016). O processo produtivo da cerâmica de revestimento é constituído de etapas de preparação da massa, conformação e secagem do suporte, aplicação das camadas de engobe e esmalte e, por fim, uma etapa queima. O engobe impermeabiliza o suporte e garante a aderência do esmalte, camada vítrea que também tem a função de impermeabilizar o revestimento, além de decorá-lo. Uma das principais matérias primas utilizadas na formulação de engobes e esmaltes é a frita cerâmica. Os esmaltes com fritas apresentam vantagens sobre os vidrados não fritados como fusão e maturação a temperatura inferior e melhor estiramento e brilho conferidos à superfície do produto (AMORÓS, 2001).

As fritas são materiais de natureza vítrea preparadas por fusão, em temperaturas elevadas (em torno de $1500^{\circ} \mathrm{C}$ ), a partir de uma mistura de matérias-primas de natureza cristalina. A massa fundida é resfriada instantaneamente em ar ou água, originando a frita propriamente dita. [SANCHES, 1997]. As fritas são submetidas a moagem e peneiramento a fim de se obter um intervalo de tamanho de partículas apropriado, mais largo ou mais estreito, dependendo do efeito desejado para o produto final (AMORÓS, 2001). As granilhas são selecionadas granulometricamente, entre 0,15 e $2 \mathrm{~mm}$. Quando a granulometria do material obtido é superior à desejada, realiza-se uma nova moagem. Quando a granulometria é inferior, o material é descartado do processo (SARABANDO; OLIVEIRA; LABRINCHA, 2011). A destinação inadequada desses resíduos pode resultar em prejuízos para a empresa e impactos ambientais, sendo um dos principais problemas acerca do processo de produção da granilha.

Uma alternativa de reutilização já adotada envolve a refusão do material e sua inclusão na formulação da própria frita que o originou. Uma segunda opção seria a incorporação do resíduo na formulação de engobes e esmaltes, o que pode resultar na redução de custos desses produtos, tornando-os mais competitivos no mercado. No entanto, é necessário um estudo que avalie o efeito da reutilização dos finos da granilha nas características técnicas e estéticas dos engobes e esmaltes. Diante disso, o presente trabalho tem como objetivo principal avaliar a viabilidade técnica e econômica da utilização do resíduo da produção da granilha na formulação de engobes e esmaltes cerâmicos.

\section{Procedimento Experimental}

Quatro diferentes resíduos passíveis de serem incorporados nas formulações de um engobe e um esmalte foram selecionados. Uma vez que um desses resíduos seja inserido em uma formulação, torna-se necessário sua disponibilidade de forma constante na indústria. Portanto, considerou-se uma previsão da quantidade 
de cada subproduto gerada mensalmente, apresentada na Tabela 1 .

Os resíduos foram queimados em duas diferentes condições: um ciclo de $25 \mathrm{~min}$ e patamar de $1100{ }^{\circ} \mathrm{C}$, comum para tipologias fabricadas por via seca, e um ciclo de $40 \mathrm{~min}$ com temperatura de queima de $1200^{\circ} \mathrm{C}$, comum para porcelanatos produzidos por via úmida. Em seguida, foram caracterizados quanto às suas principais características após queima, tais como cor, textura, brilho e fundência.

Um engobe refratário e um esmalte transparente, ambos comumente utilizados sobre suportes cerâmicos produzidos por via seca, foram selecionados para os testes de incorporação de resíduos. A quantidade com que os mesmos são produzidos na indústria também foram consideradas na seleção, uma vez que esta deve ser suficiente para permitir a incorporação de todo o resíduo produzido possível. Outro critério de seleção foi a própria formulação desses produtos, apresentadas nas Tabela 2 (esmalte) e Tabela 3 (engobe). Buscou-se trabalhar com produtos compostos por fritas com características semelhantes às fritas que originam o resíduo estudado.

A partir dos resultados da caracterização dos resíduos, foram definidos quais seriam mais interessantes para substituir alguma das matérias-primas presentes na formulação do esmalte e do engobe de referência. Após a definição dos resíduos a serem utilizados, testaram-se diferentes percentuais de utilização dos mesmos em substituição às fritas, componentes de maior custo presentes nas formulações padrão. As devidas alterações nas proporções das outras matérias-primas foram realizadas, visando-se a mínima alteração do desempenho técnico dos produtos.

As formulações padrão e as formulações desenvolvidas com a incorporação do resíduo da granilha foram pesadas e moídas em moinho de bolas tipo periquito, juntamente com água, até a obtenção do resíduo de moagem desejado. As densidades dos engobes e esmaltes foram determinadas com um picnômetro. Mediu-se o tempo de escoamento das amostras com um copo Ford $n^{\circ} 4$ para verificação de seu comportamento reológico. Por fim, foi medido o resíduo de moagem, com o auxílio de uma peneira de 325 mesh.

O engobe padrão e os engobes desenvolvidos foram aplicados, lado a lado, para facilitar sua comparação visual, utilizando-se um binil com abertura de $0,2 \mathrm{~mm}$ sobre uma base cerâmica. Uma camada de esmalte transparente foi aplicada sobre essas amostras, simulando-se uma condição industrial. $\mathrm{O}$ esmalte padrão e os esmaltes formulados foram aplicados, também lado a lado uns dos outros, utilizando-se um binil de abertura $0,3 \mathrm{~mm}$ em base cerâmica já engobada. As amostras foram queimadas em forno cerâmico a rolos de tamanho semi-industrial. As condições de queima utilizadas foram determinadas conforme as tipologias do engobe e do esmalte selecionados.

Avaliou-se, visualmente a tonalidade, brilho e textura do esmalte, além da presença de defeitos técnicos, como o fervido, os pin holes e o martelado. A caracterização visual dos engobes consistiu de uma avaliação da cor obtida, fusibilidade e mancha d'água. A dilatação térmica dos dois produtos foram avaliados, sendo determinado o ponto de amolecimento do esmalte. Além disso, para
Tabela 1. Previsão das quantidades de resíduos de granilha gerados mensalmente.

\begin{tabular}{cc}
\hline Resíduo de Granilha & $\begin{array}{c}\text { Quantidade gerada/mês } \\
\text { (kg) }\end{array}$ \\
\hline Resíduo A & 7.000 \\
\hline Resíduo B & 5.000 \\
\hline Resíduo C & 5.000 \\
Resíduo D & 15.000 \\
\hline
\end{tabular}

Tabela 2. Formulação do esmalte padrão.

\begin{tabular}{cc}
\hline Matérias-Primas & Quantidade (\%) \\
\hline FRITA 1 & 37,00 \\
\hline FRITA 2 & 44,00 \\
\hline QUARTZO & 4,00 \\
\hline FELDSPATO & 7,00 \\
\hline CAULIM & 5,50 \\
\hline ARGILA & 2,00 \\
\hline TPF & 0,35 \\
CMC & 0,15 \\
\hline
\end{tabular}

Tabela 3. Formulação do engobe padrão.

\begin{tabular}{|cc}
\hline Matérias-Primas & Quantidade (\%) \\
\hline FRITA 1 & 17,00 \\
\hline FRITA 2 & 19,00 \\
\hline TALCO & 13,50 \\
\hline FELDSPATO & 19,50 \\
\hline DIOPSÍDIO & 3,50 \\
\hline CAULIM & 7,00 \\
\hline ARGILA & 20,00 \\
\hline TPF & 0,35 \\
\hline CMC & 0,05 \\
\hline SEQ. DE SAIS & 0,10 \\
\hline
\end{tabular}

o esmalte foi realizado o ensaio de lascamento e para o engobe, determinou-se sua absorção d'água, conforme norma NBR13818, e a retração de queima, conforme procedimento interno da empresa.

Após a avaliação da viabilidade técnica, foi estimada a redução de custo que poderia ser obtida com a substituição das fritas pelo resíduo de granilha na formulação do esmalte e do engobe, estudados.

\section{Resultados e Discussões}

A Figura 1 ilustra os resultados da caracterização dos resíduos de granilha após queima a $1100{ }^{\circ} \mathrm{C}$ e $1200{ }^{\circ} \mathrm{C}$. Nota-se que, enquanto os resíduos A, B e C apresentam aspecto transparente, apesar de diferirem quanto ao grau de cobertura da cor do suporte, o resíduo D apresenta-se opaco e com pouco brilho.

Devido às semelhanças em termos de aspecto visual do resíduo A com a frita transparente presente na formulação do esmalte padrão - frita 1 - este resíduo foi selecionado para uso na formulação do novo esmalte. Formulações 

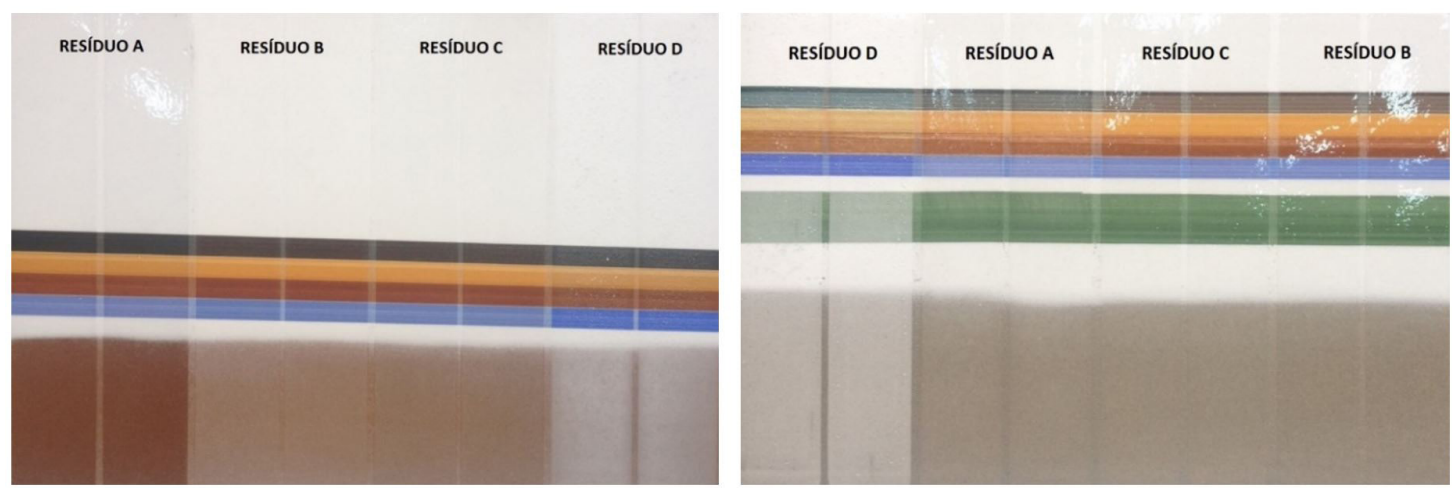

Figura 1. Aspecto visual dos resíduos após queima a $1100^{\circ} \mathrm{C}$ (esquerda) e $1200^{\circ} \mathrm{C}$ (direita).

testes foram produzidas, substituindo-se a frita 1 por diferentes percentuais desse resíduo: 2,50\%, 5,0\%, 7,5\% e $10,0 \%$. Os mesmos percentuais foram avaliados para o desenvolvimento do engobe. Nesse caso, selecionou-se o resíduo $\mathrm{B}$ que, apesar de originado de uma frita transparente, apresentou certa brancura quando queimado a $1100^{\circ} \mathrm{C}$, de forma similar à frita 1 da composição do engobe padrão.

A adição de $2,5 \%$ e $5,0 \%$ do resíduo A não trouxe mudanças significativas no aspecto do esmalte formulado, em comparação com o esmalte padrão. Os esmaltes com $7,5 \%$ e $10,0 \%$ de resíduo apresentaram maior brancura, porém uma textura mais áspera e com menos brilho. Isso sugere que o emprego do resíduo em quantidades mais elevadas tenha resultado em um esmalte com características mais refratárias que o esmalte padrão.

Para maior reaproveitamento do resíduo e maior redução de custo, a formulação ideal, dentre as avaliadas, seria a que permite a incorporação de $10 \%$ do subproduto. Para viabilizar essa opção, foram desenvolvidas formulações com as alterações necessárias nos teores das outras matérias-primas de forma a se obter um esmalte com as características mais próximas possíveis do esmalte padrão. Foram reduzidas as quantidades de outras matérias-primas refratárias da composição, como o caulim, por exemplo, e elevados os percentuais de matérias-primas mais fundentes, como o feldspato e, até mesmo, as outras fritas. Depois de alguns testes realizados chegou-se a uma formulação que resultou em um esmalte com as características desejadas, apresentada na Tabela 4.

A adição de 2,5\% do resíduo $B$ não trouxe mudanças significativas para o engobe. Com o percentual de substituição de 5,0\% obteve-se um engobe com maior fusibilidade e menor brancura em relação ao padrão, o que é explicado pela maior fusibilidade do resíduo em relação frita substituída. Com maiores percentuais de resíduo, tal diferença tornou-se ainda mais perceptível. Para viabilizar a adoção da formulação que incorporação $10 \%$ do resíduo da granilha, diminuíram-se os percentuais da frita 1 e do vidro, matérias-primas mais fundentes, e aumentaram-se os de feldspato, talco e diopsídio, com maior refratariedade. A Tabela 5 apresenta a melhor formulação testada para o engobe desenvolvido com a reutilização de $10 \%$ do resíduo $\mathrm{B}$.
Tabela 4. Esmalte teste aprovado.

\begin{tabular}{cc}
\hline Matérias-Primas & Quantidade (\%) \\
\hline FRITA 1 & 27,00 \\
\hline FRITA 2 & 46,00 \\
\hline RESÍDUO A & 10,00 \\
\hline QUARTZO & 4,00 \\
\hline FELDSPATO & 7,50 \\
\hline CAULIM & 3,00 \\
\hline ARGILA & 2,00 \\
\hline TPF & 0,35 \\
\hline CMC & 0,15 \\
\hline
\end{tabular}

As suspensões preparadas a partir das formulações do novo esmalte e novo engobe foram caracterizadas e comparadas com as suspensões obtidas a partir das formulações padrão. Com uma mesma densidade de $1,79 \mathrm{~g} / \mathrm{cm}^{3}$ para os esmaltes, houve uma redução no tempo de escoamento em copo Ford, do esmalte referência para o desenvolvido, de 55s para 48s. Essa diminuição ainda não deve prejudicar a aplicação do produto por campana e a produção de uma camada de esmalte livre de defeitos. O resíduo de moagem do esmalte formulado foi mantido entre 3,0 e 4,0\%, mesma faixa em que se encontra o resíduo medido para esmalte padrão.

Para os engobes, para uma densidade mantida a $1,77 \mathrm{~g} / \mathrm{cm}^{3}$, também houve ligeira redução no tempo de escoamento para o esmalte com resíduo, em relação ao engobe padrão, de 44s para 40s. Isso indica, novamente, que o uso do resíduo não acarreta em mudanças reológicas significativas. O resíduo de moagem foi controlado entre 0,5 e $1,0 \%$.

O engobe e o esmalte desenvolvidos foram aplicados sobre suportes cerâmicos e queimados a $1100^{\circ} \mathrm{C}$ com um ciclo de 25 minutos, condição utilizada para os produtos padrão. A Figura 2 apresenta o aspecto visual dos produtos referência e os novos desenvolvidos com resíduo de granilha após a queima. O esmalte desenvolvido apresentou ótimos resultados com relação ao brilho e à refratariedade, com textura muito próxima do esmalte padrão. Vale ressaltar que a tonalidade obtida foi menos amarelada, o que é bastante valorizado no desenvolvimento de esmaltes. 
Para o caso dos engobes, mesmo após a realização de testes, não foi possível desenvolver um produto com características idênticas ou melhores que o engobe padrão. Com alterações na formulação, obteve-se um engobe com a mesma fusibilidade que a referência, porém com menor brancura e com mancha d'água mais perceptível. À medida que se buscava corrigir estas características, o engobe desenvolvido se apresentava mais refratário, o que poderia interferir diretamente na sua retração pós queima, acarretando em mudanças na curvatura da peça. Apesar dessas questões, considera-se o desempenho do engobe desenvolvido satisfatório, já que as diferenças em relação à brancura e mancha d'água não são significativas a ponto de descaracterizar o produto.

Em relação à dilatação térmica, os resultados são satisfatórios. Como apresenta as Figuras 3 e 4, o coeficiente de dilatação para o esmalte padrão é de $65,8 \times 10^{-7 \circ} \mathrm{C}^{-1} \mathrm{e}$ de $66,6 \times 10^{-70} \mathrm{C}^{-1}$ para o esmalte com resíduo, bastante próximos. De acordo com as figuras 5 e 6 , o coeficiente de dilatação de dilatação de $94,6 \times 10^{-70} \mathrm{C}^{-1}$ do padrão foi reduzido para $92,9 \times 10^{-70} \mathrm{C}^{-1}$ para o engobe formulado. A diferença não é desprezível, mas aceitável segundo as fichas técnicas dos produtos. Para os esmaltes, os resultados da avaliação do seu ponto de amolecimento foram ótimos: $714{ }^{\circ} \mathrm{C}$ para o esmalte padrão e $713{ }^{\circ} \mathrm{C}$ para o desenvolvido.

Tabela 5. Engobe teste aprovado.

\begin{tabular}{|cc|}
\hline Matérias-Primas & Quantidade (\%) \\
\hline FRITA 1 & 5,50 \\
\hline RESÍDUO B & 10,00 \\
\hline FRITA 2 & 18,00 \\
\hline TALCO & 14,00 \\
\hline FELDSPATO & 21,00 \\
\hline DIOPSÍDIO & 4,00 \\
\hline CAULIM & 7,00 \\
\hline ARGILA & 20,00 \\
\hline TPF & 0,35 \\
\hline CMC & 0,05 \\
\hline SEQ. DE SAIS & 0,10 \\
\hline
\end{tabular}

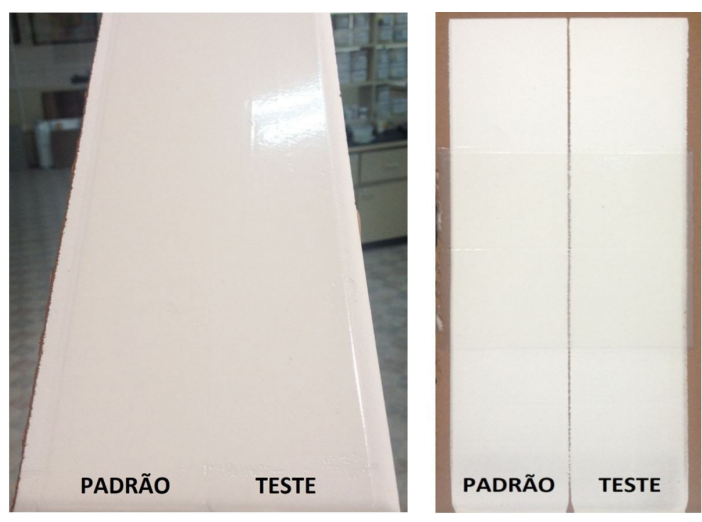

Figura 2. Esmalte padrão x esmalte desenvolvido (esquerda) e engobe padrão $\mathrm{x}$ engobe desenvolvido (direita).
Para completar a caracterização dos produtos desenvolvidos, realizou-se, ainda um ensaio de lascamento para os esmaltes, apresentado na Figura 7. Foram produzidos vários riscos na superfície do esmalte padrão e do esmalte formulado, porém nenhum deles apresentou lascamento.

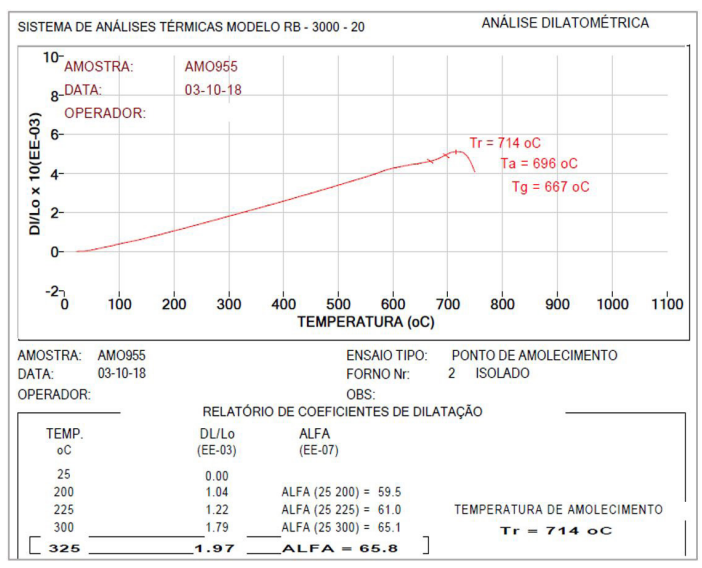

Figura 3. Laudo de dilatação do esmalte padrão.

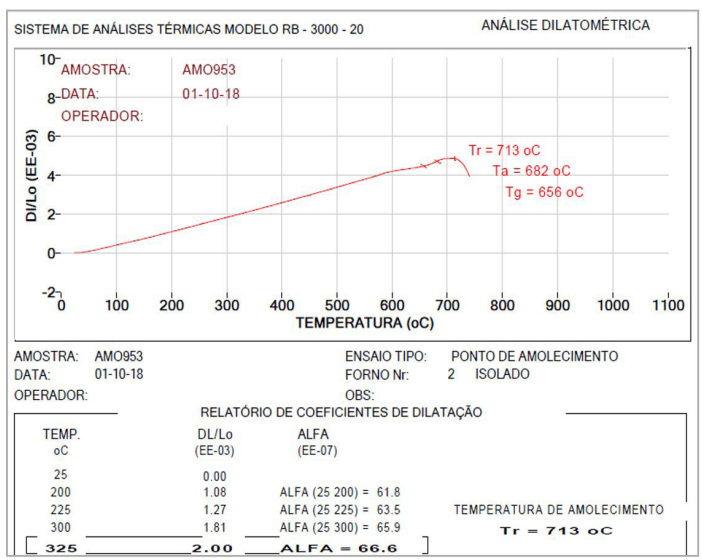

Figura 4. Laudo de dilatação do esmalte formulado.

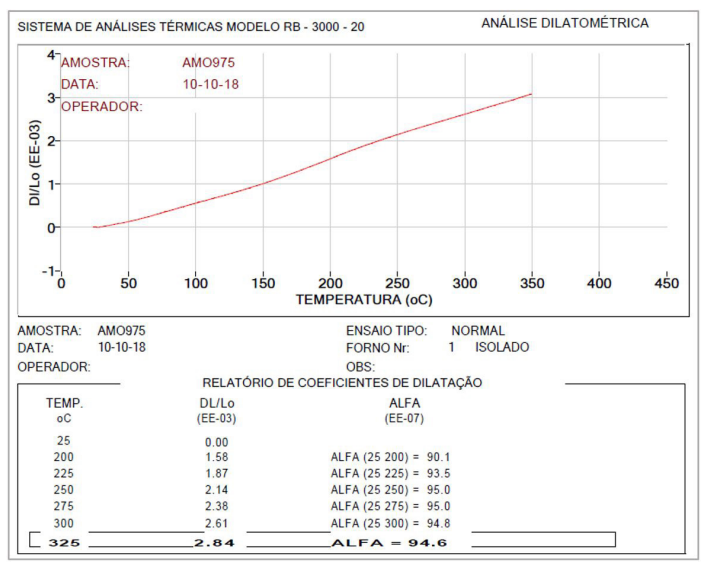

Figura 5. Laudo de dilatação do engobe padrão. 
Esse resultado é bastante satisfatório, visto que, no processo de instalação, é comum que os revestimentos sejam submetidos a cortes para serem assentados em espaços menores.

A retração de queima do engobe padrão aumentou de $4,46 \%$ para $4,49 \%$ com o uso do resíduo na formulação. A absorção de água aumentou de $12,06 \%$ para $12,72 \%$. Essas variações pequenas evidenciam a semelhança entre a fusibilidade do engobe formulado e do engobe padrão. Esse resultado é ótimo e essencial para a viabilização do uso do resíduo no engobe, visto que a fusibilidade é uma característica que influencia diretamente a curvatura final do resvestimento cerâmico.

Tendo a viabilidade técnica comprovada, a redução de custo pretendida com a substituição parcial das fritas pelo resíduo da granilha foi estimada. Considerando as formulações aprovadas, $3,57 \%$ do custo total da produção do esmalte poderia ser reduzido, enquanto para o engobe, a economia seria de $6,52 \%$. Levando em consideração que $60.000 \mathrm{~kg}$ de esmalte e $45.000 \mathrm{~kg}$ de engobe são utilizados na indústria mensalmente, uma economia significativa pode ser alcançada. Além disso, com a reutilização do

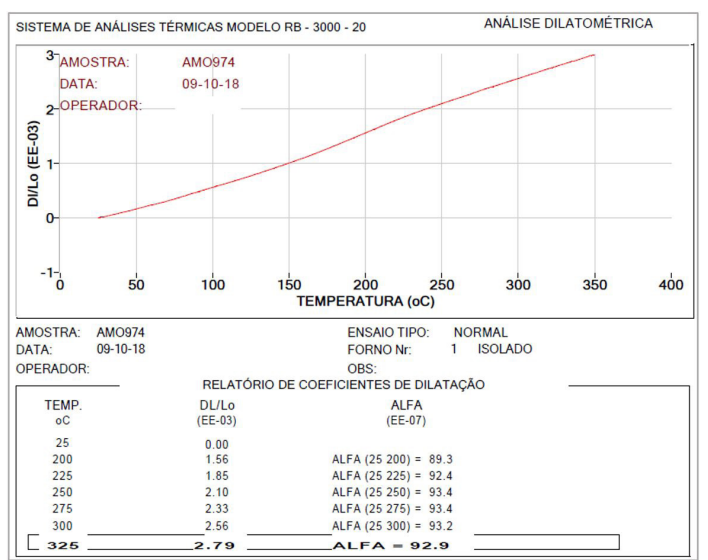

Figura 6. Laudo de dilatação do engobe formulado.

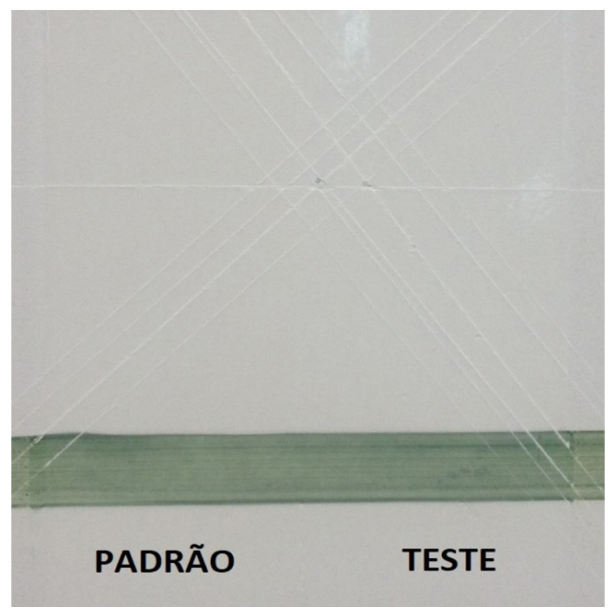

Figura 7. Ensaio de lascamento do esmalte padrão e o novo desenvolvido. resíduo, a empresa evita preocupações e gastos com sua estocagem e descarte.

\section{Conclusões}

A viabilidade técnica e econômica da reutilização de resíduos da fabricação de granilha na produção de engobes e esmaltes, em substituição a fritas presentes em sua formulação original, foram avaliadas.

Um esmalte transparente foi desenvolvido, com $10 \%$ de resíduo incorporado em substituição a uma frita presente em sua composição. O produto apresentou características muito próximas do esmalte padrão, sem adição de resíduo, obtendo-se ainda uma redução no tom amarelado, indesejado nos esmaltes.

Um engobe também foi desenvolvido, com a mesma porcentagem de substituição. Apesar de apresentar a mesma fusibilidade que o engobe padrão e outras características satisfatórias, observou-se opacidade ligeiramente menor e mancha d'água mais aparente. Apesar disso, tais divergências não foram tão significativas a ponto de prejudicar o desempenho do produto final.

Além da comprovação da viabilidade técnica, foram estimadas reduções de custo para as formulações desenvolvidas da ordem de $3,57 \%$ para o esmalte e $6,52 \%$ para o engobe. O reaproveitamento do resíduo ainda minimiza problemas relacionados ao seu estoque $\mathrm{e}$ descarte, proporcionando, além de vantagens financeiras, benefícios ambientais.

\section{Agradecimentos}

Os autores agradeçem a empresa Colorminas Colorifício e Mineração pelas matérias-primas e o acesso a seus laboratórios.

\section{Referências}

ABNT. NBR13817. Placas cerâmicas para revestimento classificação. Rio de Janeiro, 1997.3 p.

AMORÓS, José Luis. Vidrados para Pavimentos e Revestimentos Cerâmicos: Evolução e Perspectivas. Parte II. Revista Cerâmica Industrial. v. 6, n. 6, p. 18-27, 2001. Disponível em: <http://www.ceramicaindustrial.org.br/pdf/v06n06/ v6n6_3.pdf $>$. Acesso em: 22 abril 2018.

COLONETTI, Ricardo. Alves. Trajetória da Indústria de Revestimentos Cerâmicos do Sul Catarinense. Revista Cerâmica Industrial. v.21, n. 3, p. 21-25, 2016. Disponível em: <http://www.ceramicaindustrial.org.br/pdf/v21n3/ v21n3a03.pdf $>$. Acesso em: 21 abril 2018.

SANCHES, E. Matérias-primas para a Fabricação de Fritas e Esmaltes Cerâmicos. Revista Cerâmica Industrial. v. 2, n. 2/3, p. 32-40, 1997. Disponível em: <http://www. ceramicaindustrial.org.br/pdf/v02n34/v2n34_5.pdf $>$. Acesso em: 22 abril 2018.

SARABANDO, Artur. R. M.; OLIVEIRA, Helder. J. C.; LABRINCHA, João Antonio. Uso de Granilhas em Suspensão para Porcelanato. Revista Cerâmica Industrial. v. 16, n. 3, p. 11-16, 2011. Disponível em: <http://www. ceramicaindustrial.org.br/pdf/v16n3/v16n3a02.pdf $>$. Acesso em: 22 abril 2018. 